\title{
Uma apresentação crítica dos conceitos de globalização hegemônica e contra-hegemônica à luz das novas manifestações populares internacionais
}

\author{
Isabella Gonçalves Miranda \& Fábio André Diniz Merladet*
}

\begin{abstract}
Resumo: 0 presente artigo tem como objetivo dialogar com as teorias contemporâneas da democracia na era da globalização, propondo uma reflexão apurada sobre a emergência de novos fenômenos, atores e arranjos pós-nacionais. Na primeira parte é contextualizada a situação de crise da democracia na era da globalização e o problema do déficit democrático nas esferas transnacionais; em seguida, são apresentados dois projetos políticos, o hegemônico e o contra-hegemônico, que buscam redefinir os valores e procedimentos dessa prática política. Por fim, o texto debruça-se sobre as possibilidades de desenvolvimento de uma sociedade civil global capaz de democratizar as instâncias pós-nacionais, em diálogo com a renovação da teoria deliberativa.
\end{abstract}

Palavras-chave: globalização, democracia, deliberação, hegemonia, contra-hegemonia.

\section{Introdução}

No início do século XXI, o mundo inteiro assistiu a um conjunto de processos de contestação política. As variadas manifestações e os levantes populares, como as contestações à OMC (Organização Mundial do Comércio) que ocorreram 1999 em Seattle, o Fórum Social Mundial que, partindo de Porto Alegre, internacionalizou-se rapidamente, e mais recentemente, os ataques hackers, as ocupações de espaços públicos como ocorreram na Espanha com os Indignados, no Chile com o Movimento Estudantil e em Nova Iorque com o Occupy Wall Street, revelam-nos um mosaico de revoltas que, embora devam ser contextualizadas e tenham suas particularidades, trazem em comum um quadro de insatisfações diante da democracia minimalista e das lógicas de mercado hegemônicas que se globalizaram, o que se manifesta por meio de seus discursos e práticas e na defesa do que atualmente denomina-se democracia real ${ }^{1}$.

\footnotetext{
* Graduandos em Ciências Sociais - UFMG.

${ }^{1}$ Democracia real é um termo recentemente cunhado pelos novos movimentos de contestação política para denominar as aspirações e as práticas desses movimentos e levantes populares que questionam os modelos hegemônicos de democracia, a saber, os modelos minimalistas.
} 
A insatisfação geral com os procedimentos de tomada de decisões, organização da vida e formação de governos em vigor na maioria dos países tidos como democráticos, que se manifesta por meio das recentes manifestações contra-hegemônicas, tem sido objeto de ampla discussão na Ciência Política desde a década de 70, causando acalorados debates entre os que defendem a democracia minimalista e os que concebem a democracia como um conceito abrangente que integra a participação política para além da disputa por votos e cargos públicos.

Ao mesmo tempo em que se formou, desde o final do século XX, um consenso ocidental sobre a desejabilidade da democracia ${ }^{2}$, persistiu um debate amplo e difícil de conciliar em torno dos valores que essa prática política deveria abarcar e dos seus procedimentos. Por um lado, os diversos movimentos da sociedade civil e intelectuais da ciência política, que apostam em formatos participativos e deliberativos, tais como Jürgen Habermas e Claus Offe, atribuem essa crise à falta de democracia. Por outro, economistas e cientistas políticos, como Joseph Schumpeter e Samuel Huntington, mais voltados para a dimensão dos procedimentos da democracia representativa e a sua compreensão como uma disputa entre elites, atribuem dita crise ao excesso de democracia.

Para entender como se divide esse embate, recorro ao conceito de hegemonia criado por Gramsci (1987) e à sua utilização por Santos (2002), que emprega o conceito para dividir as correntes teóricas da democracia em contra-hegemônicas e hegemônicas. A corrente contra-hegemônica coloca em questão o conteúdo democrático e social do contrato social subjacente aos Estados nacionais modernos. Segundo eles, tais formatos políticos foram incapazes de gerar sociedades mais livres e igualitárias, pois haviam abandonado os ideais de soberania do povo e a participação popular em nome de um modelo elitista assentado exclusivamente na representação baseada no voto esporádico.

Essa discussão veio a aprofundar-se nas últimas décadas do século XX e início do século XXI pela emergência de práticas democráticas inovadoras que tomaram lugar nos países recém-democratizados do Sul global, como os conselhos deliberativos no Brasil, os conselhos comunais na Venezuela ou o orçamento participativo

\footnotetext{
${ }^{2}$ Embora haja ainda quem questione a democracia e suas qualidades, é inegável que, pelo menos no ocidente, ela tem sido cada vez mais o único procedimento minimamente legítimo de formação de governos.
} 
que, iniciando-se na cidade de Porto Alegre, hoje serve de inspiração para milhares de cidades em toda a América Latina e em muitos países da Europa, da África e, surpreendentemente, até mesmo nos Estados Unidos, onde experiências estão ocorrendo nas cidades de Chicago e Nova Iorque. Tais práticas abarcam novos arranjos participativos que invocam a experimentação e a criatividade da democracia pela reinserção da sociedade civil no âmbito das deliberações das políticas locais e nacionais confrontando-se com uma "concepção hegemônica da democracia" elaborada no Norte Global ${ }^{3}$.

A segunda corrente, hegemônica, fortemente representada pela Comissão Trilateral de 1975, composta pelos teóricos Samuel Huntington, Michel Crozier e Joji Watanuki, defende que a democracia está em crise por se encontrar sobrecarregada com direitos e reivindicações. Para eles, a solução para tal crise seria controlar as pressões da sociedade relativamente ao Estado, reduzindo as formas de inclusão e participação democráticas. Posteriormente assimilada pelo chamado Consenso de Washington ${ }^{4}$, essa concepção deu origem a um modelo neoliberal de Estado, em que democracia e capitalismo globalizado podiam conviver mais harmonicamente.

Em ambos os casos é denunciada uma crise do contrato social subjacente à crise da democracia. De acordo com Santos (2006), os processos sociais da globalização neoliberal estariam entre os fatores responsáveis pela crise contratual. 0 teórico defende que o contrato social moderno é a instância em que se definem os termos de inclusão e exclusão dos indivíduos dentro de um Estado Nacional, e, por isso, é em torno desses termos que, na primeira modernidade (século XX), se processaram as lutas por emancipação e justiça social. Com a globalização, são colocadas em cheque a unidade e a soberania do Estado Nação, e grande parte das decisões que

\footnotetext{
${ }^{3}$ É importante destacar que a utilização dos termos Sul e Norte ocorre como uma definição política e não geográfica. O Norte define-se basicamente pelos Estados Unidos, Canadá, Oceania e Europa, entretanto, está também nos espaços nacionais super elitizados de nações pobres. O Sul, por sua vez, é constituído pelo conjunto de todos os outros países e comunidades do globo que têm uma experiência política comum de exploração e marginalização, o que resulta em uma posição particular de subordinação na nova economia global que persiste até hoje. Esses países e comunidades seguem sendo, nesse novo modelo do capitalismo global, fonte de mão-de-obra hiper-explorada e de matéria prima mal paga.

${ }^{4}$ O Consenso de Washington é um conjunto de medidas criado no final da década de 80, logo após a dissolução da URSS e do fim da Guerra Fria, com o objetivo de expandir a visão neoliberal ao conjunto de países da América Latina. Tal "Consenso", imposto de cima para baixo, era composto por dez regras básicas, a saber: 1. Disciplina fiscal, 2. Redução dos gastos públicos, 3. Reforma tributária, 4. Juros de mercado, 5. Câmbio de mercado, 6. Abertura comercial, 7. Investimento estrangeiro direto com eliminação de restrições, 8. Privatização das estatais, 9. Desregulamentação das leis econômicas e trabalhistas, 10. Direito à propriedade intelectual.
} 
afetam a vida das pessoas agora ultrapassa a esfera nacional. Como reação a isso, várias lutas por emancipação também se deslocam para uma esfera transnacional sem, no entanto, abandonar as esferas local e regional. Surgiram também lutas políticas essencialmente globais que reivindicam, entre outras coisas, a democratização de organismos internacionais, como a ONU, o FMI e a OTAN, e do sistema financeiro global, como ocorreu recentemente por meio dos protestos em Wall Street.

Entendemos emancipação, da mesma forma que Santos, como aquelas ações que carregam a aspiração de uma sociedade em que as diferentes relações de poder sejam substituídas por relações de autoridade partilhada. Adotamos normativamente essa concepção por ser ela mais abrangente e focada mais no processo transformativo do que nos estágios finais e resultados da transformação social.

Em consonância com as ideias desse autor, procuramos indagar quais os desafios lançados pela globalização à democracia na atualidade, bem como os desafios para a construção de práticas contra-hegemônicas de democracia na esfera transnacional.

Primeiramente, analisamos os processos da globalização com base na sua classificação, feita por Boaventura de Sousa Santos, em hegemônicos e contra-hegemônicos. Em um segundo momento, discutimos as teorias da deliberação à luz de tais fenômenos. Por fim, trazemos os atuais movimentos e as manifestações de uma contra-hegemonia global para a discussão da democracia deliberativa a fim de indicar o que poderia ser uma semente de uma sociedade civil globalmente articulada capaz de interpelar os poderes instituídos. Trata-se, portanto, de uma análise das possibilidades de organização social e popular que possam levar à emergência de lutas políticas em nível transnacional.

\section{Os processos da globalização}

O conceito de globalização foi e é largamente utilizado para caracterizar um projeto ideológico de integração de todo o mundo em um sistema único de mercado baseado na lógica da economia capitalista e na alta circulação de bens, informações, produtos e pessoas. Segundo essa concepção ideologizada de globalização, o livre mercado resultaria no desenvolvimento econômico de todos os países e na ampla difusão das inovações tecnológicas, que aumentariam a qualidade de vida dos seres humanos. 
Contudo, a integração das diferentes pessoas e dos diferentes Estados no mundo globalizado não se dá de forma horizontal, contínua e homogênea, mas por meio de transformações complexas que afetam de maneira diversa classes/identidades em diferentes espaços.

Como indica a Comissão Mundial sobre a Dimensão Social da Globalização, a globalização neoliberal hegemônica não é benéfica para todos como a sua ideologia faz crer. Na verdade, ela ocorre conjuntamente a uma série de transformações positivas e negativas que afetam, de maneira desigual, países e pessoas no interior de cada país.

\begin{abstract}
Nos últimos trinta anos, a desigualdade na distribuição dos rendimentos entre países aumentou dramaticamente. A diferença de rendimento entre o quinto mais rico e o quinto mais pobre era, em 1960, de 30 para 1, em 1990, de 60 para 1 e, em 1997, de 74 para 1. As 200 pessoas mais ricas do mundo aumentaram para mais do dobro a sua riqueza entre 1994 e 1998 [...] A riqueza dos três mais ricos bilionários do mundo excede a soma do produto interno bruto dos 48 países menos desenvolvidos do mundo (PNUD, 2001) [...] Segundo o Relatório do Programa para o Desenvolvimento das Nações Unidas de 2001 (PNUD, 2001), mais de 1,2 bilhão de pessoas (pouco menos do que 1/4 da população mundial) vivem na pobreza absoluta, ou seja, com um rendimento inferior a um dólar por dia e outros 2,8 bilhões vivem apenas com o dobro desse rendimento. (CoMISSÃo MUNDIAL SOBRE A DIMENSÃo GLOBAL DA GLOBALIZAÇÃo apud Santos, 2001, p. 40).
\end{abstract}

Para entender os processos de globalização, é preciso ligar as teorias sobre a globalização a situações concretas, buscando entender o seu impacto na vida de diferentes grupos humanos, bem como a forma como estes reagem a essas transformações. Conectando as análises locais às globais, podem-se construir teorias sobre a globalização bem mais fundamentadas. É preciso fazer estudos que nos aproximem do entendimento do fenômeno que Michael Budawoy define como Grounded Globalization:

We wanted to construct perspectives on globalization from below, as experienced on the ground, the ways globalization attaches itself to everyday life, the way neoliberalism becomes common sense. [...] we search for theories that would help us stretch from local to global (BUDAwoy, 2000, p. 339).

Boaventura de Sousa Santos (2001), ao operar tal análise, esboça um quadro teórico que, dialogando com a teoria de Gramsci, divide os processos de globalização em hegemônicos e contra-hegemônicos, incorporando a conflitualidade nas dinâmicas de transição dos modelos de Estado, de Economia e dos modelos culturais e so- 
cietais. Os processos hegemônicos, segundo ele, são orientados para a acumulação e apropriação capitalistas, e a sua hegemonia assenta-se na identificação dos interesses do bloco no poder com interesses gerais, ou seja, em um consenso que favorece os grupos dominantes. Os processos contra-hegemônicos, por sua vez, agrupam os diversos movimentos locais, por vezes articulados globalmente, que lutam contra os efeitos perversos da globalização hegemônica e são orientados para a solidariedade e o bem comum. Apesar de distintos, esses processos são complexos e, por vezes, interpenetram-se e confundem-se, sendo necessário analisá-los de caso a caso.

\section{A globalização hegemônica e a democracia}

A globalização hegemônica não é um processo novo. Muitos teóricos, como Fernando Coronil, Anibal Quijano, Edgard Lander e Immanuel Wallerstein argumentam que o processo de integração das diferentes partes do mundo em um sistema de acumulação de capital iniciou-se logo no século XV com a descoberta da América. Desde aquela época, os diferentes espaços foram sendo organizados em dominantes e dominados, o que transformou as periferias e semi-periferias do mundo em espaços de subordinação política e econômica para a expropriação de riquezas por parte dos países centrais, processo que, obviamente, não foi livre de contradições e oposições ${ }^{5}$. Foi, contudo, a partir da década de 1970 até os dias atuais, que a globalização hegemônica intensificou o processo de integração mundial com o avanço das tecnologias de comunicação e transporte que possibilitou transações internacionais mais rápidas e intensas. Essa integração, nos últimos anos, vem acompanhada da difusão dos pressupostos e das práticas econômicas e políticas do neoliberalismo.

Assentado no chamado Consenso de Washington, o neoliberalismo defende medidas diversas para alavancar a economia de mercado, o sistema financeiro e a concorrência em nível mundial, apresentando soluções para a crise do período antecessor, marcado por forte intervenção estatal na vida econômica e social ${ }^{6}$. Na

\footnotetext{
${ }^{5}$ Há, na historia dos países dominados, incontáveis demonstrações de resistência das classes populares, das minorias étnicas, dos escravos e da população como um todo contra a dominação exercida pelas elites que cooptavam com o projeto de expropriação e subordinação durante o colonialismo e, até mesmo, na fase pós-colonial. Se olharmos de forma mais profunda e minuciosa para a história da América Latina, percebemos que não houve nem um único dia em que não ocorreu alguma expressão de resistência ao poder e ao dinheiro

${ }^{6}$ Embora seja legítimo dizer que ninguém mais acredita no Consenso de Washington, o fato é que a doutrina neoliberal de desregulamentação da economia continua na pauta de reformas impostas pelos organismos in-
} 
prática, o que neoliberalismo busca defender é um Estado mínimo para as políticas sociais e, ao mesmo tempo, um Estado máximo para a Economia. Além disso, esse paradigma considera a desigualdade um fator essencial para o bom funcionamento do mercado sendo, por isso, até mesmo desejável. Em suma, a acumulação flexível neoliberal baseia-se na desigualdade e a produz incessantemente.

Em um contexto de grande pessimismo e desesperança que marcou o fim do último século, com o fracasso das experiências socialistas ocorridas no Leste Europeu, com a chamada "morte das utopias" e com o enfraquecimento dos movimentos de resistência e da esquerda tradicional, o neoliberalismo realizou um enorme esforço para apresentar-se como a única forma de organização social, política e econômica possível no mundo. Dessa forma, as medidas que propõe passaram a ser empregadas com intensidade a partir dos anos 1980, orientando-se, em termos gerais, para a liberalização do comércio internacional, a expansão dos investimentos externos, a crescente privatização de serviços públicos, a flexibilização de direitos trabalhistas e a crescente desregulação da economia.

David Harvey (2008), em seu texto O neoliberalismo: história e implicações, mostra como as mudanças estruturais na economia, promovidas pelas reformas neoliberais, deslocam o poder de classe, com a perda da qualidade de vida pela parcela da população correspondente à classe média e à classe baixa, e com a ascensão de um novo grupo de pessoas muito ricas relacionadas com as operações no sistema financeiro e com os novos ramos da produção, como as novas tecnologias de informação, a biotecnologia, as multinacionais de produção de energia, de cultivo de sementes transgênicas, etc. Esse grupo poderia ser definido como uma espécie de classe hegemônica transnacional "porque seus membros, apesar da diversidade dos seus interesses setoriais, partilham uma situação comum de privilégio socioeconômico e um interesse comum de classe nas relações do poder político e do controle social que são intrínsecas ao modo de produção capitalista" (Evans apud Santos, 2001, p. 38). Nos últimos anos, essa dita classe conseguiu manter uma relação privilegiada com o poder estatal dos diferentes países e com os organismos internacionais, constituindo uma enorme capacidade de influenciar processos políticos.

ternacionais aos países subdesenvolvidos. De qualquer maneira, a questão agora não é saber se o Consenso de Washington ainda vive, é saber o que deverá substituí-lo. 
Outras consequências importantes da reestruturação da ordem mundial ainda em curso são a perda de centralidade e poder de decisão do Estado em detrimento das empresas, dos organismos internacionais (União Europeia, OTAN ONU, etc) e dos organismos financeiros (OMC, Banco Mundial, FMI); a redução da autonomia política e soberania efetiva dos Estados periféricos e semiperiféricos em detrimento dos Estados centrais; a formação de monopólios baseados em grandes corporações e multinacionais; as modificações na organização das empresas e na distribuição global do trabalho e a expansão para várias partes do mundo do modelo de democracia liberal e das legislações inspiradas em países "centrais"7.

Nesse contexto, surge um novo marco regulatório pós-nacional que integra os novos e antigos atores da globalização hegemônica, baseado na inter-relação entre os setores público e privado transnacionais, com forte presença dos organismos internacionais políticos, financeiros e regulatórios. A esse marco, a literatura tem dado o nome de governança:

Governo significa um conjunto de atividades que são levadas a cabo por autoridades formais, pelo poder público [...] enquanto governança se refere a atividades assentes em valores partilhados, resultantes ou não de responsabilidades impostas formalmente pela lei, e que não requerem inevitavelmente o apoio do poder político para ultrapassar as resistências e garantir o seu efetivo cumprimento. (Rosenau apud Pureza, 2002, p. 101).

Santos (2006) defende que a governança é a matriz política da globalização neoliberal. Ela joga com ideais de abertura, participação e horizontalidade, sendo uma rede auto-ativada, porém somente pode ser acessada por um conjunto de atores seletos identificados com interesses comuns de acumulação capitalista. Como não aceita o binômio dentro/fora característico dos contratos sociais, a governança dá pouca ou nenhuma chance aos excluídos de converterem-se em atores incluídos. Eles são entendidos mais como inexistentes do que como atores em possível via de inclusão. Em seu marco fluido tampouco ficam claras questões como "quem governa?", “a quem se deve responsabilizar determinadas decisões?", "qual é o poder de enforcement das instituições reguladoras pós-nacionais diante de países hegemôni-

${ }^{7}$ Utilizo os termos central, periférico e semiperiférico conforme o sentido dado a esses termos por Wallerstein (2004). 
cos?", ou mesmo, "é possível se pensar em espaços deliberativos democráticos na matriz da governança?":

\begin{abstract}
Para identificar o significado político da governança neoliberal, temos que prestar atenção não apenas àquilo que ela diz, mas também àquilo que silencia. São os seguintes os silêncios mais importantes da matriz da governança: as transformações sociais, a participação popular, o contrato social, a justiça social, as relações de poder e a conflitualidade social (SANTOS, 2006, p. 13).
\end{abstract}

A ausência de espaços deliberativos democráticos institucionalizados em nível global, a existência de esferas não reguladas democraticamente, como o mercado financeiro, as assimetrias de poder de pressão das instituições reguladoras internacionais diante dos países centrais em relação aos países periféricos, a precariedade do princípio da isonomia nas instituições internacionais, como o Conselho de Segurança da ONU, e outras questões indicam que existe um déficit democrático na esfera transnacional.

As grandes preocupações da democracia no século XX que, enquadradas no território nacional, discutiam questões como soberania estatal e soberania popular, accountability, representação, autorização e sociedade civil nacional, deixam de ter um sentido claro quando enquadrados na esfera internacional. Nancy Fraser (2009), em seus estudos recentes, identificou esse problema de enquadramento que, segundo ela, está gerando um novo tipo de injustiça social de caráter metapolítico. Para a autora, justiça requer arranjos sociais que permitam a todos participarem como pares na vida social. A dimensão política da justiça diz respeito ao palco em que se expressam as lutas por reconhecimento e redistribuição, a critérios de pertencimento social, regras da decisão e procedimentos. Segundo ela, as reivindicações por justiça ao longo do século XX aconteciam no interior dos Estados territoriais e concerniam as relações entre os cidadãos: "as reivindicações por redistribuição geralmente se focalizavam em desigualdades econômicas dentro dos Estados territoriais, as demandas por reconhecimento geralmente se dirigiam às hierarquias de status internas" (FrASER, 2009, p. 12).

O problema é que, com a globalização econômica, os processos sociais que afetam a vida das pessoas transbordam as fronteiras nacionais. Contudo, os afetados ainda não conseguem influir ou lutar por justiça em tais esferas de maneira eficiente, pois não existe uma efetiva institucionalidade democrática em nível transnacio- 
nal. Dessa forma, ela conclui que as lutas por justiça devem agora abarcar as lutas contra o mau enquadramento, por uma democracia metapolítica.

Como resposta a esse déficit democrático e também como consequência da globalização, os velhos e os novos atores da sociedade civil, como os hackers, os occupiers e também os sindicatos, passam a se organizarem em novas arenas democráticas para a formulação de uma luta política global contra-hegemônica que, várias vezes, carrega traços anti-globalização, anti-neoliberalismo e anti-imperialismo, e tecem um esboço do que poderia ser um espaço público pós-nacional.

\section{A globalização contra-hegemônica e a democracia}

O capitalismo demonstra, ao longo de sua história, uma enorme capacidade para adaptar-se às sistemáticas crises e para aprofundar-se ainda mais. No entanto, para além das muitas crises no capitalismo, pode ser que estejamos assistindo neste momento à crise do capitalismo, que não consegue mais dar respostas para os problemas que criou. A manifestação mais evidente dessa crise do capitalismo advém da constatação atual da sua capacidade destruidora que, se não for retraída, deverá ter consequências ecológicas e humanas drásticas, como o aumento da desigualdade e a redução da biodiversidade.

Atualmente, estamos passando por tempos de crise do sistema capitalista e crise de legitimidade das instituições democráticas formais, ambas estão dando lugar à emergência de novas formas de participação política. Desde as manifestações de Seattle em 1999 e de Genova em 2001, o mundo inteiro assiste a um processo de proliferação das manifestações contra-hegemônicas, seguida da construção de Fóruns mundiais, regionais e locais, da renovação do pensamento de esquerda e dos movimentos sociais tradicionais. Essa intensa renovação tornou possível a organização de movimentos e de atores contra-hegemônicos em nível transnacional, como ocorreu, por exemplo, no caso dos povos indígenas do Equador em luta contra as multinacionais petroleiras, a reorganização de sindicatos globalmente, a mobilização para as manifestações na Grécia e para as ocupações que têm ocorrido na Espanha, em Wall Street e em diversas cidades do mundo, assim como tornou possível o surgimento de novos e numerosos movimentos sociais e grupos da sociedade civil que reivindicam uma outra realidade diferente da que existe.

Essas diversas manifestações de resistência que propõem alternativas ao sistema em curso atuando no nível local cada vez mais estão se organizando e se articu- 
lando no nível global construindo uma governança contra-hegemônica insurgente, que de acordo com Santos:

[...] implica a articulação e a coordenação entre uma imensa variedade de movimentos sociais e de organizações da sociedade civil, com a finalidade de combinar estratégias e táticas, de definir agendas, e ainda de planejar e levar a efeito ações coletivas (SANTos, 2006, p. 22).

Apesar de distintos, esses movimentos convergem as suas lutas de resistência no combate à dominação do capital, ao neoliberalismo e ao imperialismo. Isso ocorre, pois todos eles, de alguma forma, lutam contra as consequências da universalização da submissão ao capitalismo globalizado e a lógica da acumulação. Ao negarem a perspectiva liberal, que define as pessoas como seres econômicos de racionalidade calculista que deveriam buscar sua emancipação individual por meio das oportunidades oferecidas pelo mercado e afirmarem uma perspectiva das pessoas como seres sociais capazes de se organizarem em processos de solidariedade e ação coletiva, eles restauram a crença na capacidade humana de alterar o curso da história.

Boaventura de Sousa Santos (2002) identifica algumas das características centrais desses novos movimentos sociais com base na análise do Movimento Zapatista que, segundo ele, é uma manifestação fundadora desse projeto contra-hegemônico: 1) a ampliação do conceito de opressão pela identificação de que a exclusão social não é única e monolítica, não diz respeito a uma classe e sim a toda a humanidade, e por isso, devem ser plurais as lutas emancipatórias; 2) a exigência de equivalência entre a igualdade e a diferença (os indivíduos têm o direito de expressar a sua pluralidade em condições iguais de direitos e dignidade e têm de ser tratados como diferentes quando a igualdade os oprime); 3) a valorização da via democrática, participativa, "desde abaixo" para a conquista do poder e para a realização de inovações no Estado, com a construção de vias mais diretas; 4) a construção de um "cosmopolitismo subalterno" que envolve ações que combatem a opressão não apenas atacando o centro, o Estado e a Empresa, mas o vasto conjunto de interações sociais estruturadas pela desigualdade de poder.

A expressão mais forte da articulação desses movimentos na atualidade é o Fórum Social Mundial (FSM) que é levado a cabo em conformidade com a carta de princípios de Porto Alegre, contra as diversas formas de exclusão e opressão provocadas ou possibilitadas pela atual fase do capitalismo, conhecida como globaliza- 
ção neoliberal. Disseminando o princípio da incompletude, segundo o qual não pode existir um só ator no processo de transformação social, mas vários em decorrência da complexidade do mundo atual e da diversidade das formas de opressão, o FSM preocupa-se em não dar prioridade a nenhuma organização e abre espaço para um diálogo horizontal intermovimentos. Isso é o que se pode perceber com a ênfase dada a algumas instâncias de diálogos e trocas de saberes, como a Assembleia dos Movimentos Sociais que ocorre a cada Fórum e a Cúpula dos Povos para o Rio mais 20, que ocorreu no Fórum Social Temático de 2012. Por meio da escuta mútua, do compartilhamento de angústias, esperanças e objetivos, torna-se possível a superação de antigas concepções que viam a diversidade como um obstáculo à unidade e à igualdade e pode-se construir espaços de convivência e de aprendizagem mútuos entre os diversos atores sociais para "Um Outro Mundo Possível”.

As mais diversas propostas desses grupos e movimentos têm buscado intensificar, aprofundar e (re)significar a democracia, quer reivindicando a legitimidade da democracia participativa, quer pressionando as instituições da democracia representativa no sentido de torná-las mais inclusivas, ou ainda, buscando formas de complementaridade mais densas entre a democracia participativa e a representativa. Tratam-se de tentativas diversas, nos planos prático e teórico, de criar uma nova institucionalidade da democracia o que envolve, primeiramente, a ampliação do cânone democrático. A democracia passa, assim, a ser pensada como uma prática social e não somente como um método de constituição de governos. Isso significa ampliar as esferas de participação democrática e de exercício da soberania popular com os novos arranjos institucionais participativos, que permitem o controle dos cidadãos sobre orçamentos, sobre medidas administrativas do governo, sobre a execução de políticas sociais e, por que não em um futuro, das próprias decisões do Estado acerca da economia? Significa também criar novas formas de representação, que sejam capazes de incluir agendas de identidades específicas, de minorias na nação como, por exemplo, o reconhecimento de movimentos sociais como novos e legítimos atores políticos.

Esses movimentos, buscando também superar as estruturas hierárquicas, autoritárias e pouco participativas, criam novos espaços de abrangência para as práticas democráticas. A busca da autogestão e do convívio horizontal nas ocupações de espaços públicos e nos espaços do Fórum Social Mundial, em especial o Acampamento Intercontinental da Juventude, transparecem uma forma especial de organi- 
zação das lutas por emancipação social que ensaiam novas formas de organização que querem ver no trabalho, nos governos, no Estado, nas escolas, nas casas, no mercado, nas diversas organizações e nas associações da sociedade civil, reestruturando os movimentos sociais tradicionais, em especial o sindicato, tornando-os mais horizontal e aberto ao diálogo com outros movimentos.

Uma das contribuições dos movimentos sociais novos ou renovados da atualidade tem sido a de ampliar os espaços onde se dão relações horizontais e dialógicas entre as pessoas, espaços onde se desenvolve uma cultura cívica, ou uma cidadania social para o século XXI, mais ativa, participativa, politizada e crítica, capaz de interpelar os poderes instalados (ESTANQUE, 2006).

Ao mesmo tempo em que tentam democratizar o Estado, construindo uma nova gramática de relação entre Estado e Sociedade, esses movimentos e essas organizações da sociedade civil articulam-se e operam lutas em nível global. As manifestações em Seattle e Gênova contra a OMC e o próprio Fórum Social Mundial são exemplos de ações articuladas globalmente que esboçam o que poderia vir a ser considerado um espaço público deliberativo pós-nacional.

Antes, contudo, é preciso tentar enquadrar a teoria da democracia deliberativa às esferas transnacionais, já que estas foram pensadas dentro de um espaço territorial nacional.

\section{Repensando a democracia deliberativa em uma esfera pública pós-nacional}

A democracia deliberativa surge como uma teoria que se contrapõe à concepção hegemônica da democracia centrada na agregação de pessoas por meio do voto. Ela defende que, antes e para além das eleições, existe um espaço denominado esfera pública, onde os indivíduos e grupos são capazes de tecer, por meio de discussões, suas opiniões e preferências, valores e identidades.

Simone Chambers (2009, p. 240) define deliberação como "o debate e a discussão que têm como propósito produzir opiniões racionais e bem informadas nas quais os participantes são convidados a revisar preferências à luz da discussão de novas informações e das demandas feitas pelos demais participantes". Ângela Marques (2009, p. 15), no mesmo sentido, considera que "a deliberação pode ser compreendida como uma atividade discursiva capaz de conectar esferas comunicativas formais e informais, nas quais diferentes atores e discursos estabelecem um diálogo, que tem por principal objetivo a avaliação e a compreensão de um problema coletivo ou de uma questão de interesse geral". 
Para que tal processo ocorra com legitimidade e simetria, Avritzer (2009) defende que algumas regras e princípios normativos devem ser respeitados: a) igualdade, b) publicidade, c) reciprocidade, d) reflexividade, e) accountability, f) autonomia, g) ausência de coerção, h) respeito mútuo.

Os grandes encontros das organizações civis e dos movimentos sociais nacionais e internacionais, nos quais pessoas de todo o mundo discutem estratégias políticas fundadas em diferentes concepções de mundo e traçam, muitas vezes, ações globais conjuntas, tais como o Fórum Social Mundial, podem significar a emergência dessa esfera pública acima descrita. Leonardo Avritzer, que também teoriza a dimensão pós-nacional dos movimentos da sociedade civil, defende que nesses espaços de encontro e fóruns transnacionais, assiste-se à "operação um elemento próprio dos espaços políticos nacionais: a agregação de atores sociais com o objetivo de impedir a ação de atores antagônicos" (AvRITZER, 2002, p. 115).

O Fórum Social Mundial (FSM), além de outras tantas articulações transnacionais contra-hegemônicas, como as mídias alternativas e as articulações globais de movimentos locais, podem indicar a existência de um espaço público transnacional em gestação nesse início de século XXI com potenciais de democratização das esferas nacional e transnacional. Entretanto, encontramos algumas barreiras teóricas e práticas para tecer tais afirmações.

Antes de qualquer coisa, existe o problema da identidade, que corresponde a uma questão de enquadramento, fator decisivo para a delimitação de uma sociedade civil. Para alguns, a democracia deliberativa precisa de um demos relativamente coerente e vinculado, que compartilhe uma identidade coletiva e, por isso, a democracia realmente não seria apropriada para a esfera internacional ${ }^{8}$.

De acordo com Habermas, "qualquer comunidade política que deseja entender a si pró-
pria enquanto uma democracia precisa, ao menos, traçar uma distinção entre membros
e não membros [...] Mesmo se tal comunidade está estruturada sobre princípios uni-
versalistas de um Estado constitucional democrático, ela ainda compõe uma identidade
coletiva, no sentido de que interpreta e realiza esses princípios universalistas à luz de
sua própria história e no contexto de sua própria forma de vida particular. Esse auto-en-
tendimento ético-político dos cidadãos de uma vida democrática está faltando em uma
comunidade inclusiva e mundial de cidadãos" (HABERMAS apud Chambers, 2009, p. 255).

${ }^{8}$ Ver Tompson (apud Chambers, 2009). 
Tais afirmações nos deixam em uma posição difícil diante do novo paradigma da governança neoliberal. Por isso, cabe questionar o princípio da identidade nacional como pré-condição para a democracia. Por acreditarmos que o debate acerca das pré-condições à democracia nos leva sempre a mais a retrocessos do que a avanços, recorremos a teóricos que compreendem a diferença e diversidade, antes como riqueza do que como barreira ao desenvolvimento democrático.

Iris Marion Young (2001), por exemplo, critica a unidade como pressuposto e como objetivo da prática deliberativa. Segundo ela, as ideias de bem comum e racionalidade neutra politicamente não existem, pois até mesmo os discursos carregam relações de poder implícitas que podem gerar a dominação da perspectiva do grupo dominante sobre os demais, a exclusão e a perpetuação de privilégios. Além do mais, a autora defende que a unidade como condição prévia retira a riqueza da pluralidade, impossibilitando a transcendência e o aprendizado com o diferente. Ela defende que "as diferenças de cultura, perspectiva social ou comprometimento particularista sejam compreendidos como recursos a serem usados na compreensão da discussão democrática, não como divisões a serem superadas” (YounG, 2001, p. 369).

Um princípio recente do pensamento de Nancy Fraser, o "princípio de todos os afetados", segundo o qual todos os afetados por uma política tenham o direito à palavra, pode ser bastante útil para pensar a democracia deliberativa em um contexto em que políticas são pensadas no nível internacional.

Essas perspectivas parecem-nos mais consonantes aos processos deliberativos no interior do FSM, que rejeitam visões totalizantes de emancipação social e partem da ideia da incompletude de todas as formas de pensamento, condição fundamental para a transcendência e para o aprendizado com o outro. Ao não definir o "Outro Mundo Possível”, o FSM abre as possibilidades para que todos os diferentes projetos políticos se expressem e dialoguem em seu interior, atuando como uma verdadeira esfera pública democrática para a expressão do pensamento e das práticas contra-hegemônicas.

Para dar conta de fenômenos como o FSM, teóricos, como Dryzek e Bohman, estão desenvolvendo modelos pós-nacionais de democracia centrados não em uma vontade coletiva, mas na ação de tornar instituições e governos mais responsivos (accountable) diante da pluralidade de uma sociedade civil transnacional reunida por causas comuns. Para tal, desenvolvem a concepção de democracia descentralizada, que também é proposta por outros autores, como Warren, na qual: 
[...] uma pluralidade de forças de comunidades e grupos sociais informais se engaje em campanhas globais de persistência discursiva. Uma democracia descentralizada delega a voz democrática a uma sociedade civil amplamente descoordenada e à esfera pública (WARREN apud Chambers, 2009, p. 278).

Essa concepção, embora interessante, não é suficiente. Retomando Fraser e a sua aposta na construção de uma democracia metapolítica, defendo que a sociedade civil global somente será capaz de influir verdadeiramente nas decisões políticas nos níveis transnacionais se for capaz de pressionar para a construção de instituições democráticas e participativas em nível global, espaços institucionalizados onde um processo deliberativo mais estável e eficaz, do ponto de vista da efetivação das preferências, pode ocorrer.

Tal questão perpassa uma discussão dentro do campo da teoria da democracia deliberativa acerca das formas como o espaço público se torna capaz de influir nas esferas políticas. Para alguns teóricos, como Habermas, as discussões oriundas das esferas públicas são capazes de penetrar na esfera política influindo nas decisões governamentais. Outros teóricos, como Leonardo Avritzer, defendem que as influências indiretas da esfera pública na esfera política são insuficientes para garantir a participação dos grupos sociais nas discussões e deliberações políticas, é preciso que a sociedade civil pressione o poder instituído para que sejam criados arranjos participativos, espaços institucionalizados.

\section{Conclusão}

Diante das recentes alterações no quadro social, cultural, político e econômico mundial, decorrentes em grande parte dos processos da globalização, tanto a teoria como a prática democrática em crise está, paradoxalmente, passando por um rico e diversificado processo de transformação. Na tentativa de contribuir para a análise desse processo, neste artigo, foram apresentadas as duas formas de globalização com que nos defrontamos no momento presente.

Por um lado, temos a estratégia da globalização hegemônica de difusão de uma "democracia de baixa intensidade"9 nas esferas nacionais dos diversos países

9 Termo utilizado por Boaventura de Sousa Santos no seminário de celebração dos 10 anos do Fórum Social Mundial em Porto Alegre. 
do mundo, em prejuízo aos processos de deliberação pública, accoutability societal ${ }^{10}$ e soberania popular. Também parece ser parte de sua estratégia a construção de uma matriz de Governança que, na maioria dos casos, só permite uma participação transnacional seletiva e pouco democrática.

Por outro lado, assistimos a uma globalização contra-hegemônica que procura radicalizar o conceito e a prática democrática ampliando-a para todos os espaços, desde as relações cotidianas entre os indivíduos até as esferas globais, passando pelas lutas locais e nacionais.

A globalização contra-hegemônica, apesar de ainda fraca e em processo de formação, tem méritos significativos. Ela conseguiu criar e dar visibilidade a diversos projetos revolucionários de sociedade; pôde denunciar situações diversas de opressão e de produção de injustiças em todo mundo; e deu forças às lutas locais dos movimentos sociais. Ela está criando um espaço para a construção conjunta de um futuro pelos diversos movimentos e atores sociais incorporando abrangentes demandas, cosmovisões, noções de opressão e projetos alternativos de mundo. A indeterminação que carrega a frase promulgada pelo FSM, "um outro mundo é possível", é marca fundamental das relações democráticas, onde as diferenças podem dialogar para a construção de algo novo.

É certo que essa globalização contra-hegemônica enfrenta e enfrentará enormes desafios para a instituição de uma verdadeira democracia em todos os níveis. Se a contra-hegemonia questiona a democracia liberal, é porque pretende radicalizar a palavra democracia e transformá-la em um imperativo de liberdade, de realização humana e de dignidade de vida para todos.

\section{Referências}

Avritzer, L. (2002). “Globalização e espaços públicos: a não regulação como estratégia de hegemonia global”. Revista Crítica de Ciências Sociais, n. 63.

. (2009). "Prefácio". In: Marques, A. C. S. (Org.). A deliberação pública e suas dimensões sociais, políticas e comunicativas. São Paulo, Autêntica.

\footnotetext{
${ }^{10}$ Accountability exercido pela sociedade civil.
} 
BudAwoy, M. (2000). “Grounded Globalization”. In: University of California Press.

. Global Ethnography. London,

Chambers, S. (2009). "A teoria democrática deliberativa". In: MARQues, A. C. S. (Org.). A deliberação pública e suas dimensões sociais, políticas e comunicativas. São Paulo, Autêntica.

Crozier, M. J.; Huntington, S. P.; Watanuki, J. (1975). The crisis of democracy: report on the governability of democracies to the trilateral commission. New York, New York University.

ESTANQUE, E. (2006). "A questão social e a democracia no século XXI. Participação cívica, desigualdades sociais e sindicalismo”. Revista Finisterra, Lisboa, vol. 55-56-57.

GRAmSCI, A. (1987). Cadernos do Cárcere: os intelectuais e a organização da cultura. 5a edição. Rio de Janeiro, Civilização Brasileira.

HARVEY, D. (2008). "Liberdade é apenas mais uma palavra". In: _.. O neoliberalismo: história e implicações. Tradução: Adail Sobral e Maria Stela Gonçalves. São Paulo, Loyola.

MARques, A. C. S. (2009). "As interseções entre o processo comunicativo e a deliberação pública”. In: _.. A deliberação pública e suas dimensões sociais, políticas e comunicativas. São Paulo, Autêntica.

Pureza, J. M. (2002). “Quem governa? Portugal e as novas teias da governação global". Revista Crítica de Ciências Sociais, n. 63.

SANTos, B. S. (2001). “Os processos de Globalização”. In:__. Globalização: fatalidade ou utopia?. Porto, Afrontamentos.

___ (2002). Fórum Social Mundial: manual de uso. São Paulo, Cortez.

tez.

. (2006). A gramática do tempo: para uma nova cultura política. São Paulo, Cor-

(2008). “El Foro Social Mundial y la izquierda global”. Informe El Viejo Topo, n. 240.

SANToS, B. S.; AvRitzer, L. (2002). "Introdução para ampliar o cânone democrático". In: SAnTos, B. S (Org.). Democratizar a democracia: os caminhos da democracia participativa. Rio de Janeiro, Civilização Brasileira.

YounG, I. M. (2001). “A comunicação e o outro: além da democracia deliberativa”. In: SouzA, J (Org.). Democracia hoje: novos desafios para a teoria democrática contemporânea. Brasília, Ed. UnB.

WALLERSTEIN, I. (2004). World-Systems analysis: an introduction. Durham, Duke University Press.

Recebido em setembro/2011

Aprovado em março/2012 